\title{
Monitoring of Aquatic Environments Using Passive Samplers
}

\author{
L. Chimuka*, E. Cukrowska and H. Tutu
}

School of Chemistry, University of the Witwatersrand, P/Bag 3, WITS 2050, Johannesburg, South Africa

\begin{abstract}
A review is given on the development of passive samplers for aquatic environments. Passive samplers that are simple and easy to use and with minimal consumption of organic solvents to desorb the analytes from the trapping media are focused. New developments in quality assurance procedures are highlighted.
\end{abstract}

\section{INTRODUCTION}

Monitoring of the presence and levels of various organic chemicals in water bodies is important as its gives vital information on the toxic risks associated with them. The common approach is to collect part of the environmental media which is later analyzed for potential pollutants in the laboratory. This approach among other advantages helps to control the extraction parameters and therefore gives quality results. However, information obtained from grab environmental samples is only about concentration levels at the time of sampling and may fail to account for episodic contamination. This can be addressed by collecting many representative samples over a time period but with increased cost of analysis. Many laboratories especially in developing countries are under funded and therefore cannot afford expensive analysis. A much better approach is to obtain time-weighted average (TWA) concentration of pollutants using passive samplers. Passive sampling devices allow measurement of an average bioavailable concentration over a long period, on the order of a day to several weeks [1-4]. This gives a better picture of the concentration levels in an ecosystem as it reduces the error caused by short-term concentration variations. Passive samplers are cheap and can easily be developed over a large area of the environmental media and most of them combine sampling and sample preparation in one step.

Passive samplers mimic biological membranes and consist of a receiving phase, with high affinity for organic contaminants, separated from aquatic/air environment by a diffusion limiting membrane [2-4]. They are calibrated in the laboratory so the TWA concentrations of organic pollutants can be determined in the field. Calibration however may not be very accurate due to environmental factors such as turbulence and temperature.

Biomonitoring organisms have been used as alternative passive samplers and have a major advantage in that they reflect the true impact of the condition of the environment [5-8]. They do not need any deployment and preconcentrate the compounds through bioconcentration. However, they have some limitations in their use as passive samplers. Biomonitoring organisms cannot survive in certain environmental conditions and age, size, sex and physical condition

*Address correspondence to this author at the School of Chemistry, University of the Witwatersrand, P/Bag 3, WITS 2050, Johannesburg, South Africa;

E-mails: luke.chimuka@chem.wits.ac.za and luke_chimuka@hotmail.com might affect the uptake rates of compounds [9]. The organisms should be in abundance and for long term monitoring should be less mobile in the environment [5]. The trapped compounds also need to be re-extracted and often require an additional clean-up step thus consuming both time and organic solvents.

A number of review papers [10-14] have been written on passive samplers for water monitoring indicating the growing interest in this area. However, aspects of the simplicity, selectivity and the need for passive samplers to consume less organic solvents have not been fully addressed. For this reason, this review is aimed at discussing these aspects.

\section{THEORY}

The trapping of chemicals in the passive sampling devices has been described as simple diffusion and partitioning between two compartments of the receiving phase and external environment separated by a diffusion-limiting membrane $[4,10,11]$. In order to have maximum sensitivity, a sampler design should have a high $\mathrm{A} / \mathrm{L}$ ratio where $\mathrm{A}$ is the area and $\mathrm{L}$ is the length of the sampler. Tube type samplers are therefore less sensitive compared to badge type samplers. The latter have high $\mathrm{A} / \mathrm{L}$ ratio and most passive samplers are therefore configured in the badge type. Whatever design is employed, passive samplers mostly have a barrier between the sampled medium and the receiving phase. The barrier determines the rate at which analyte molecules are collected in the receiving phase. Some barriers have defined openings resulting into diffusion-based samplers. Others have the barrier in the form of a non porous membrane, referred to as permeation-based samplers [10]. Some factors that influence the uptake rate are sampler design, physico-chemical properties of the analytes and environmental variables (e.g., water turbulence, temperature and biofouling) [10].

The process of chemical movement from the sample into the trapping media has been described as simple diffusion and partitioning between two compartments of the receiving phase and external environment [4,10,11]. Equations shown below are used in the calibration of the sampler in the equilibrium (1) and kinetic regimes (2) [10].

$$
\begin{aligned}
& \mathrm{CP}(\mathrm{t})=\mathrm{CW}\left(\mathrm{k}_{1} / \mathrm{k}_{2}\right) \\
& \mathrm{CP}(\mathrm{t})=\mathrm{C}_{\mathrm{W}_{1}} \mathrm{t}
\end{aligned}
$$

where $C_{P(t)}$ is the concentration extracted in the sampler at exposure time $\mathrm{t}, \mathrm{CW}$ is the analyte concentration in the 
aqueous environment. $\mathrm{k}_{1}$ and $\mathrm{k}_{2}$ are the uptake and offload rate constants.

Many passive samplers have been operated at the equilibrium regime such as semi-permeable devices (SPMDs) [10]. The sampler is deployed long enough so that a thermodynamic equilibrium is established between the chemicals in the environmental medium and receiving phase.

For passive samplers that work in the kinetic regime, it is assumed that the rate of mass transfer to the receiving phase is linearly proportional to the difference between the chemical activity of the contaminant in the environmental media and that in the receiving phase [10]. Chemcatcher $[4,15,16]$, MESCO [17] and membrane-assisted passive (MAPs) [18] are such samplers working in the kinetic regime. It is also possible to operate the SPMD in the kinetic regime as long as it is not deployed long enough for the analytes to reach equilibrium [19].

\section{QUALITY CONTROL}

It is very important that the concentration determined using the sampling devices reflect the true picture in the environmental media. Quality control procedures should address issues such as contamination (use of blanks and controls) and loss of the trapped analytes, accuracy and precision of the results. Inspection for signs of puncture, discoloring or any malfunctioning upon retrieval helps to see any possible sources of contamination and/or loss of the trapped analytes [12, 14]. Blanks and control samples are also used for identification of any contamination from the process [12, 14].

Accuracy and precision of the results may be difficult to obtain due to certain environmental parameters such as turbulence, biofouling and temperature. Therefore, it is easy to obtain good precision $(<5 \%)$ between replicates when samplers are calibrated in the laboratory rather than in the field. The precision of some samplers has been reviewed recently [14]. In this review it was noted that the average percentage relative standard deviations for aquatic passive samplers ranged from $10 \%-32 \%$ [14].

The extent to which turbulence affects uptake kinetics depends on factors such as sampler material, hydrophobicity of the compound and environmental flow rates. Generally, for membrane based passive samplers, permeation of compounds through the membrane is seen as the rate-limiting step and is more pronounced for polar compounds (logKow $<2$, where $\log$ Kow is the $\log$ of the octanol-water partition coefficient) (membrane/permeation controlled samplers). At high turbulence, the uptake rates for such compounds are reduced. On the other hand, for non-polar compounds (logKow $>3$ ), diffusion through the unstirred layer and sampler controls the mass transfer (donor/diffusional controlled) [20]. Once turbulence occurs in the environmental media, the unstirred layer becomes thin and therefore enhances the uptake of non polar compounds by the sampler.

Matrix interferences can influence the accuracy and precision of any extraction process. For passive samplers, the major problem is biofouling [2,10], defined as the growth of bacteria or other various flora and fauna on the surface of the sampler during deployment. This results in a secondary layer on the surface with different uptake kinetics which often increases the mass transfer resistance. The problem is compounded by random formation of biofilms. Biofilms can also block the membrane pores in the diffusion-limiting membrane. Some studies [21] have been done on the effect of biofouling on the uptake of trace organic contaminants by semi-permeable devices (SPMDs). The results showed that uptake of contaminants by SPMDs were severely reduced by as much as $50 \%$ under biofouling conditions compared to controls.

The movement of compounds through a barrier such as membranes is diffusion controlled which in turn is affected by the temperature. The effect of water temperature over a range of $4^{\circ} \mathrm{C}$ to $20^{\circ} \mathrm{C}$ in a Chemcatcher passive sampler has been studied by Kingston et al. [4]. The study involved the Chemcatcher with two different limiting membranes, a polysulfone and a polyethylene with the same $47 \mathrm{~mm} \mathrm{C18} \mathrm{Em-}$ pore disk as the receiving phase. Higher sampling rates were observed at high temperature than at low temperature. The effects of temperature on sampling rates have been observed in other samplers such as SPMDs [22] and membrane enclosed sorptive coating (MESCO) [17]. Laboratory optimization of a passive sampler should therefore be done at a temperature similar to that in the real environment.

Another problem related to quality control in passive samplers for water monitoring is the limited commercial suppliers [23]. Very few passive samplers for water monitoring have been commercialized. However many of them have patents and are being developed for possible commercialization. Lack of commercial suppliers for passive samplers means it is difficult to compare the results of the same sampler performed in different laboratories for similar compounds as the construction may not be identical.

The use of permeability reference compounds (PRCs) is now commonly seen as one promising way to account for quality control in passive samplers [10,24-26]. Similar to internal standards, these reference compounds are added to the trapping media prior to the deployment of the sampler and correct for any changes in uptake rates due to turbulence, biofouling and temperature. The use of permeability reference compounds has recently been studied in detail in a Chemcatcher [15] and MESCO [27] passive samplers. In this case the uptake rate of target compounds was correlated to their deuterated analogues (PRC) under similar conditions. Very good correlations were obtained between uptake and offload kinetic parameters of the analytes and their deuteriated parts [15, 27]. Fig. (1) demonstrates such correlation obtained in a Chemcatcher [15]. However, it was observed that the use of PRCs is applicable to moderate/low affinity compounds for the receiving phase, for which a significant offload can be measured within the time period of the experiment $[15,22]$. Another way to account for turbulence is to enclose the sampler in a container that reduces the effects of turbulence, a technique commonly used in air sampling [1]. In this case the container should not encourage the growth of biofilms and therefore the sampler has to be calibrated in the presence of this enclosure. Some organic filled dialysis samplers have been reported to reduce biofouling by slowly seeping out the organic liquid through the membrane [3]. Proper choice of the sampler design has also been reported to reduce biofouling [28]. 


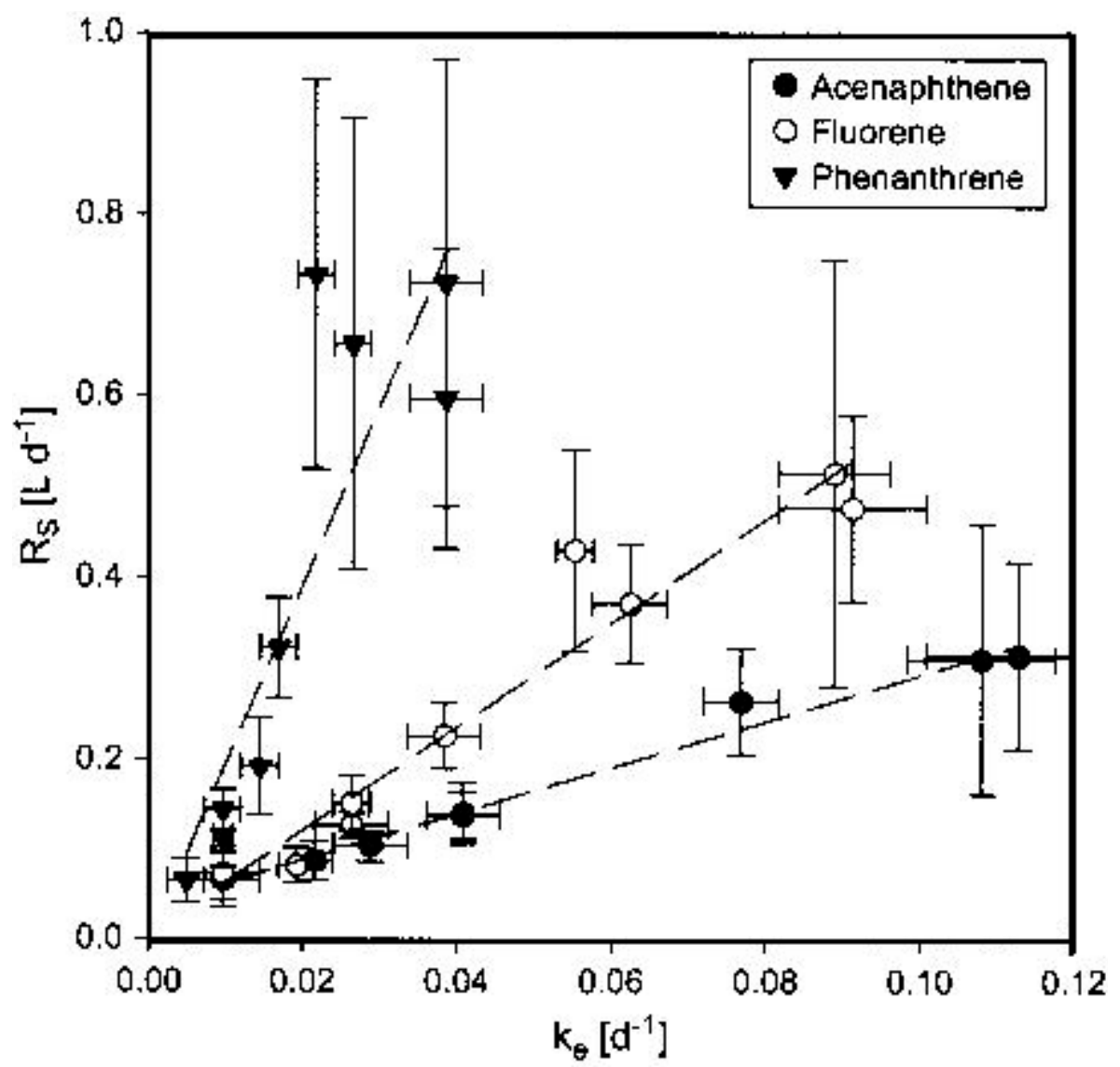

Fig. (1). Correlation between sampling rates Rs of three polycyclic aromatic hydrocarbons and offload rate constants, $\mathrm{K}_{\mathrm{e}}$ of their perdeuterated analogues (PRCs) in a Chemcatcher. From ref. [15] with permission from Elsevier.

\section{DIFFERENT PASSIVE SAMPLERS}

There are a number of passive samplers that have been developed for sampling compounds in water bodies. Reviews indicate a growing interest in this area $[10,14]$. Emphasis on simplicity and requiring no further clean-up and/ or re-extraction of the analytes from the receiving phase is stressed.

\section{Chemcatcher}

This patented sampler uses the commercially available solid phase extraction C18 Empore disks as receiving phase $[4,15]$. The partitioning of the analytes onto the sorbent and their subsequent desorption is similar to the solid phase extraction technique. The sampler is therefore simple and easy to use with little consumption of organic solvents. Two separate prototype systems have been described, one suitable for the sampling of non polar organic compounds with logKow partition coefficients values greater than 4 and the other for polar species with $\operatorname{logKow}$ values between 2 and 4 [4]. Both systems used the same receiving phase but different ratelimiting membranes. The use of well-known and commercially available receiving phase makes this sampler promising [15]. is reported to have calibrated the Chemcatcher passive sampler for monitoring of priority organic pollutants in water. The modified sampler was calibrated for monitoring of hydrophobic micropollutants such as poly aromatic hydrocarbons (PAHs) and some organochlorine pesticides in water. Environmental factors such as turbulence and tem- perature were studied in a flow-through system under controlled conditions. PRCs were also used to correct for environmental factors. This detailed study on the use of PRCs first revealed that offload kinetics followed a first order decay (Fig. 2) except for two compounds (D10-pyrene and D12-benzo[a]anthracene) whose fits were poor due to slow release. Secondly, a good correlation was obtained for the uptake of analytes and offload of their labeled analogue PRCs even with various analyte/PRC combinations. Therefore, in situ calibration of the passive samplers seems to be the most promising approach to assure quality of the data especially for quantification purposes. In another recent study, the exchange kinetics in the Chemcatcher were modeled to obtain a better understanding of the mechanism of the accumulation process and to enable measurements of TWA concentrations of compounds in the field [16]. The sampling rates for various poly aromatic hydrocarbons and some organochlorine pesticides were plotted against their logPow values $[15,16]$. In this case a bell shaped relationship was obtained even for the desorption sampling rates for PRCs. Sampling rates increased with $\log$ Pow value reaching a maximum at about $\log$ Pow value of 5.0 and thereafter started decreasing [16].

\section{Membrane Enclosed Sorptive Coating (MESCO)}

The MESCO passive sampler uses a stir bar coated with poly(dimethylsiloxane) (PDMS) enclosed in a dialysis membrane bag as receiving phase [17]. The stir bar used as a receiving phase is similar to the one in stir bar sorptive extrac- 


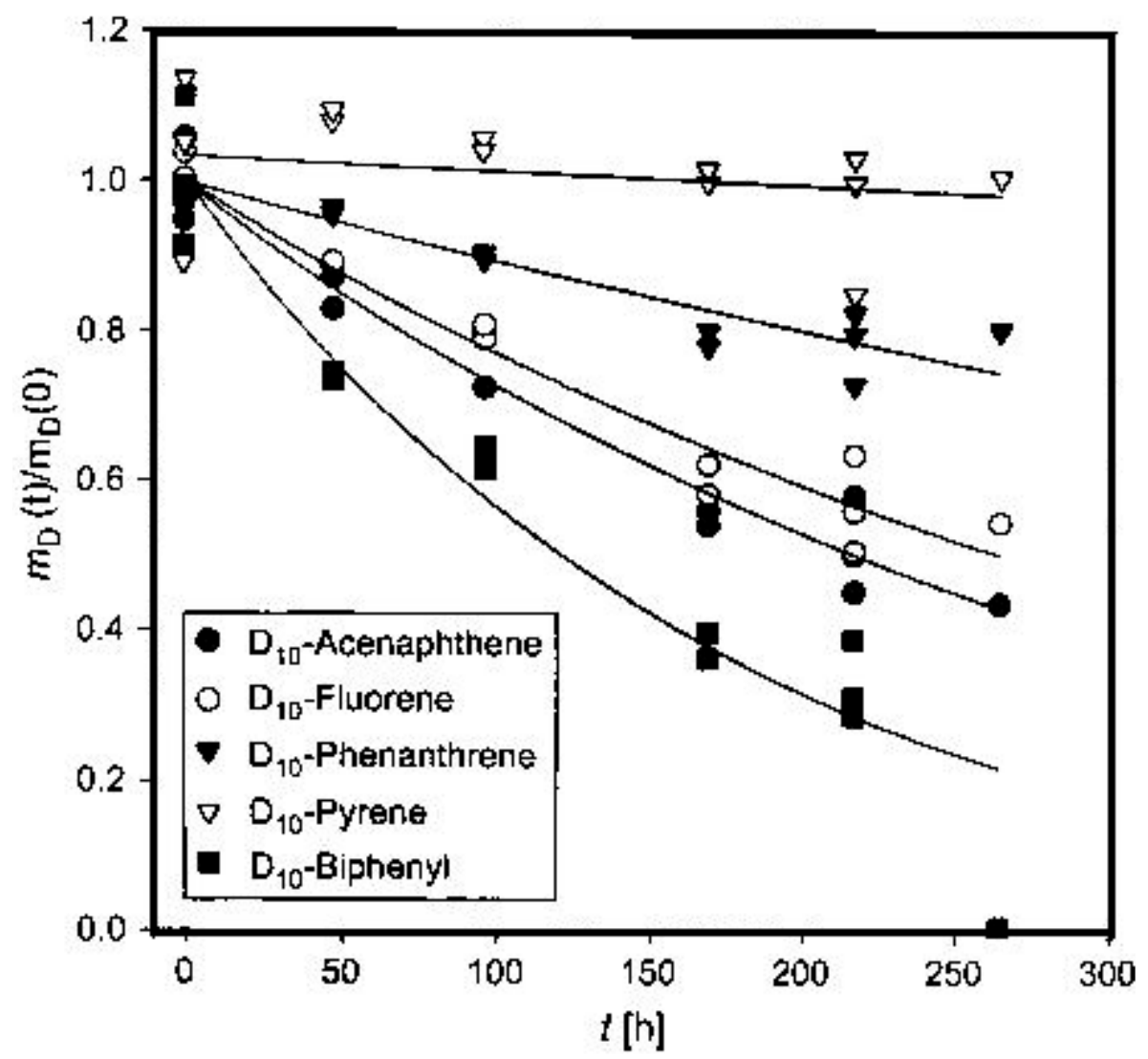

Fig. (2). Typical offload curves of PRCs from the Chemcatcher sampler. From ref. [15] with permission from Elsevier.

tion (SBSE) technique [29]. It combines the advantages of the passive sampling approach with solventless preconcentration of organic solutes from aqueous matrices and subsequent desorption of the sequestered analytes on line with capillary gas chromatography. It avoids clean up of extracts required for other samplers and whole extract is injected. The sampler is therefore quite attractive. Injection of the entire extract makes it quite sensitive despite the small surface area and volume of the sampler.

The passive sampler was tested for integrative sampling of hydrophobic persistent organic pollutants in the laboratory. Linear uptake rates of all test compounds were observed within one week of exposure period [17]. The MESCO has recently been calibrated and tested for field performance of persistent organic pollutants in water including some poly chlorinated biphenyls (PCBs) and PAHs [27]. Satisfactory linear regression fits were obtained for the uptake kinetics (Fig. 3) with correlation coefficients (r) ranging from 0.79 to 0.99 except for PCB 138, fluoranthene and pyrene for which $r$ values ranged from 0.59 to 0.69 in one of the experiments [27]. The coefficient of variation (CV) of the calculated slopes of uptake curves ranged from $5-25 \%$ with few exceptions of one experiment where it was between 33 and $40 \%$ for PCB 138, fluoranthene and pyrene. Turbulence was evaluated as well as in situ calibration to account for its effects on uptake kinetics. Flow rates of 8,35 and 68 $\mathrm{cm}$ min-1 were used to study the effect of turbulence on uptake kinetics. A one way ANOVA test was used to investigate any significant difference between the sampling rates of individual compounds under varying water conditions. The results of this test were mixed as for some compounds; an increasing sampling rate with increasing flow velocity was obtained. For other compounds, a decrease in sampling rate with increasing flow velocity was observed while others showed no pattern [27]. The observed differences in this case were attributed to the error introduced by the process of determining the sampling rates and not due to the hydrodynamics. Overall, the hydrodynamics tested did not affect the sampling rates much and also showed the robustness of the sampler. From theory, it is known that once the flow velocity is increased, the thickness of the boundary layer between the water and sampler surface decreases. The sampling rates are therefore supposed to increase for hydrophobic compounds whose mass transfer is limited by the aqueous boundary layer. For polar compounds, dissolution into the sampler can limit the uptake rates at high velocity and therefore sampling rates are supposed to decrease. This is common with samplers containing non-porous hydrophobic membranes as barriers to the receiving phase. Desorption of chemicals from the sampler using PRCs were found to be similar to the absorption of the compounds onto the sampler under the same exposure conditions just like in the Chemcatcher [15].

A new MESCO that uses a silicone collector instead of a stir bar coated with poly(dimethylsiloxane) (PDMS) has been reported by Paschke et al. [30]. The sampler consists of a lay flat membrane strip, $15 \mathrm{~cm} \mathrm{x} 3 \mathrm{~cm}$ with $100 \mu \mathrm{m}$ thickness. The $8 \mathrm{~cm} \times 4 \mathrm{~cm}$ of this consisted of $50 \mu \mathrm{m}$ thickness. The strip is segmented by heat-sealing into four and two uniform parts, respectively. Each segment $(2 \mathrm{~cm}$ long) contains a $15 \mathrm{~mm}$ long piece of pre-conditioned silicone rods (SR). The advantage of this sampler is the high capacity of the collection phase and its inexpensiveness. The silicone rods 


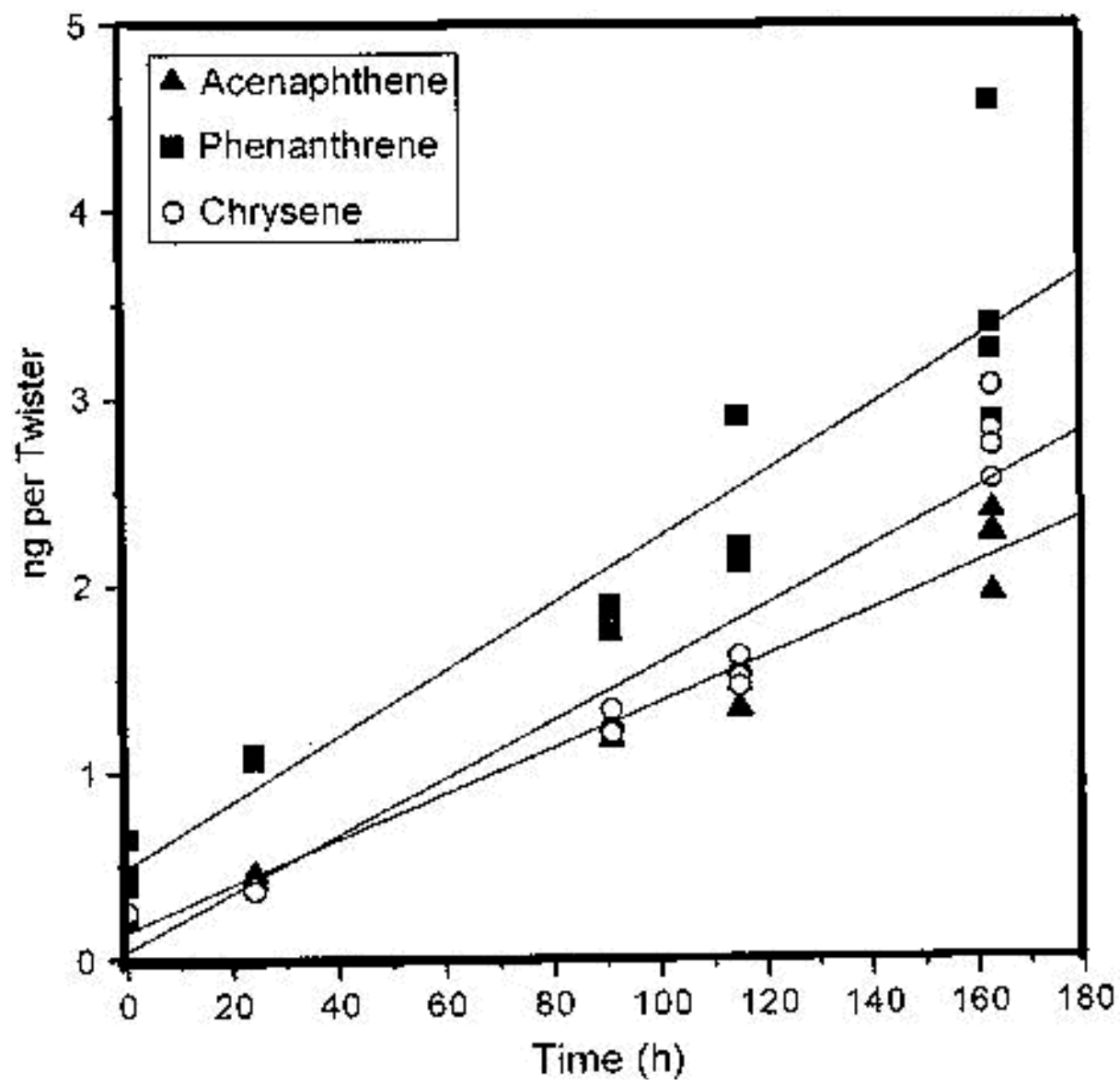

Fig. (3). Uptake of selected PAHs by the Twister based MESCO sampler. Taken from ref. [17] with permission from Elsevier.

were later thermally desorbed into gas chromatography system just in the previous MESCO sampler. Linear uptake rates were reported after 14 days exposure to selected chlorinated organic compounds and poly cyclic aromatic hydrocarbons.

\section{Membrane Assisted Passive Sampler (MAPS)}

Another sampler based on silicone rubber hollow fibre membrane has been tested using model compounds in the laboratory [18]. The MAPS uses the principle similar to that developed in supported liquid membrane for extraction of

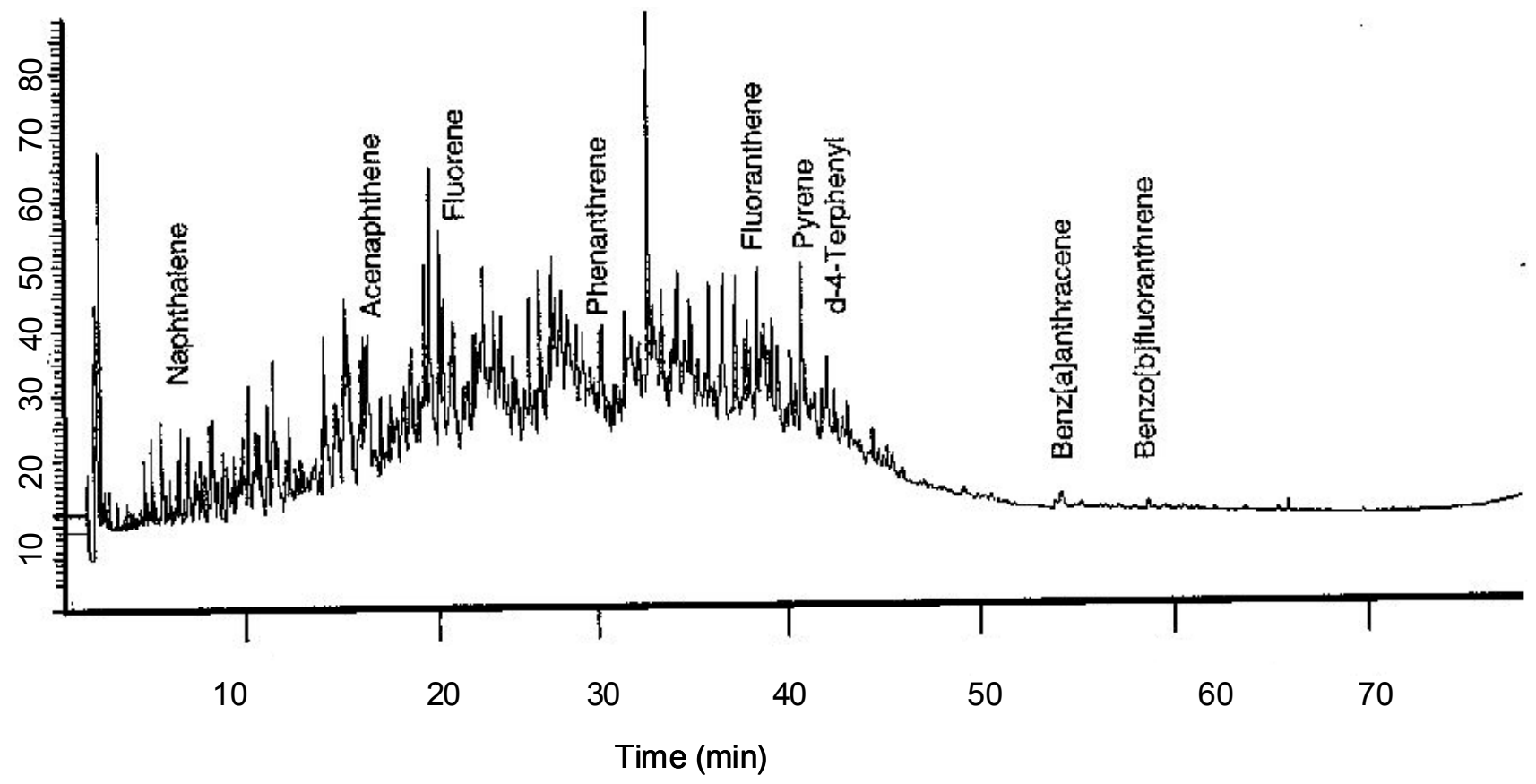

Fig. (4). Chromatogram obtained after sampling with SPMD. Taken from ref. [12] with permission from Elsevier. 
ionizable organic compounds [31,32]. In this test, a thin walled silicone rubber tube with dimension $0.15-\mathrm{cm}$ (I.D) $\mathrm{x}$ $0.24-\mathrm{cm}$ (O.D) x $48 \mathrm{~cm}$ was used. The inside of the tube is filled with an aqueous solution at an appropriate $\mathrm{pH}$. The tube is then sealed of both ends and then immersed in a water sample.

The silicone membrane is hydrophobic and therefore non-polar organic compounds easily dissolve into it. In order for the ionizable permeating compounds to be trapped in the aqueous receiving phase, the $\mathrm{pH}$ is adjusted such that the compounds are ionized and trapped. Its major advantages are its simplicity and low cost, its high selectivity since only ionizable organic compounds are trapped. Moreover, it does not use organic solvents. Since it is very selective, no further clean-up of the extract is required except for possible $\mathrm{pH}$ adjustments before injecting the extract into a High Performance Liquid Chromatograph. Fig. (5) demonstrates the selectivity of the sampler. In principle, the sampler should trap

(a)

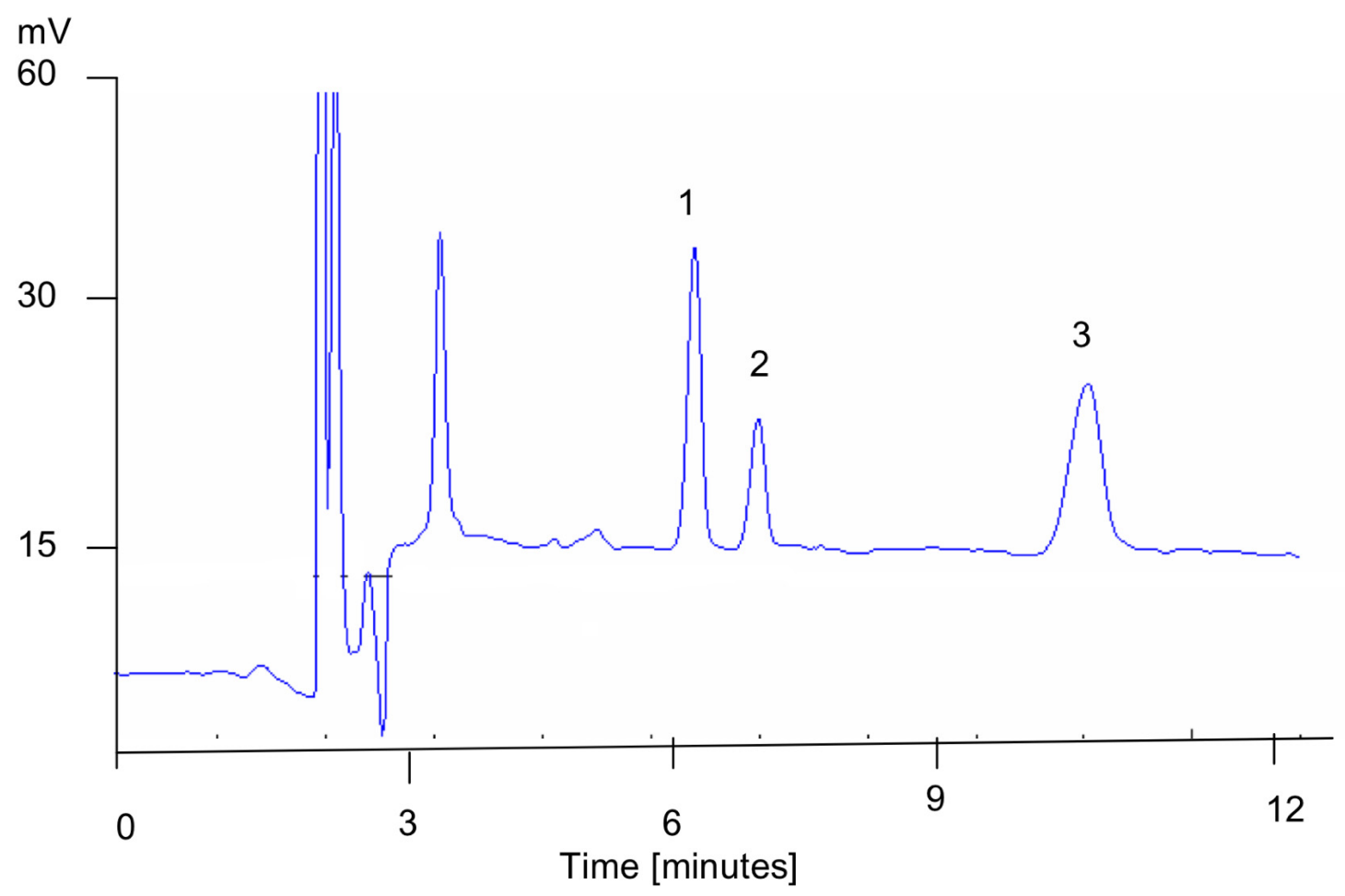

(b)

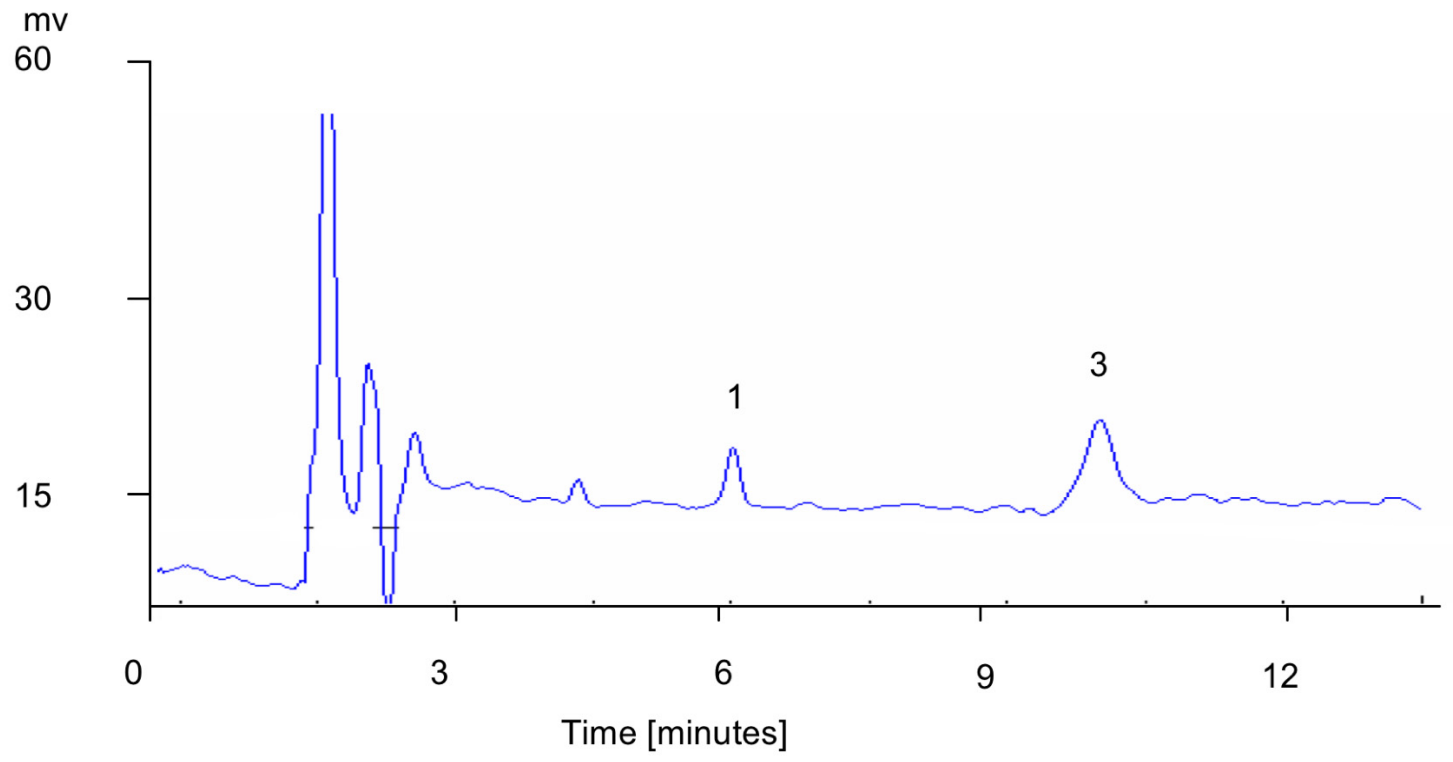

Fig. (5). Chromatogram obtained after sampling with MAPS for 72 hours with deionized water (a) and river water (b) spiked with 10 ppb mixture of 2-chlorophenol (1), 4-chlorophenol (2) and 2,4-dichlorophenol. Taken from ref. [18]. 
only ionisable organic compounds belonging to the same family at a time.

By reversing the conditions in the acceptor phase to acidic $\mathrm{pH}$, the sampler can be used to trap basic ionizable organic compounds too. Its disadvantage is that only ionizable organic compounds can be trapped. However, the silicone rubber traps neutral or uncharged compounds from the water sample. These can also be re-extracted from the membrane using organic solvents and analyzed if needed. Fig. (6) shows that the sampler is independent of the sample concentration extracted. The calculated sampling rates in $\mu \mathrm{Lh}^{-1}$ were found to be 507 for 2-chlorophenol and 707 for 2,4 dichlorophenol which are comparable to those reported in the MESCO and CHEMCATCHER. The MAPS has also been tested for linearity over a 72-hour sampling period (Fig. 7). Detection limits (three times signal to noise ratio) ranged from 0.05 to about $1 \mathrm{ugL}^{-1}$ on UV detection with photodiode detector.

\section{Polar Organic Chemical Integrative Sampler (POCIS)}

The POCIS sampler was described by Alvarez et al. [33]. It consists of a solid receiving phase material enclosed in microporous polyethersulphone diffusion - limiting membrane. It is one of the water samplers that have got a commercial sampler (EST. Inc). Unlike other samplers with only one type of solid receiving material, this contains a mixture of three solid phase sorbents (Isolute ENV, polystyrene divinyl benzene and Ambersorb 1500 carbon) dispersed on S-X3 biobeads. This combination of sorbents allows the sampler to monitor hydrophilic contaminants such as pesticides, prescription and over the counter drugs, steroids, hormones, antibiotics and personal care products (EST. Inc). The sampler has advantages in that it also uses minimal organic solvents to desorb the trapped analytes from the adsorbent. The sampler has been compared with standard column sampling for organic contaminants associated with wastewater effluents [34]. It has also been recently used to screen oestrogenic hormones from headwater streams near livestock farms [35]. In this case, the adsorbent was eluted with $40 \mathrm{ml}$ of analyti- cal grade extraction solvent (methanol) and later reduced to 1 $\mathrm{ml}$ by an evaporation system.

\section{Semi Permeable Membrane Devices (SPMDs)}

The SPMD is perhaps the most common passive sampler in use today. Its design and study was first published by Huckins et al. [2]. Since then, a number of studies have been performed on them and details can be found in review papers $[8,11,12]$. It is also commercially available (EST Inc). SPMDs consist of a lay flat tubing made of low-density polyethylene (LDPE) filled with a high molecular weight synthetic lipid, triolein. The LDPE is non porous but has transient cavities with typical size of $1 \mathrm{~nm}$ [10]. The selectivity of the sampler is based on the size of the molecules and their ability to dissolve into the membrane. Large macromolecules, ionic compounds and polar compounds do not dissolve into the membrane and are therefore excluded. Compounds with $\operatorname{logKow}>3$ are ideal for trapping in triolein $[12,36]$. Its major advantages are that it is very versatile as it can be used to sample water, soil and air pollutants and can withstand harsh environmental conditions. The major shortcoming of SPMDs is the time needed to re-extract the trapped compounds from triolein and the use of large organic solvents. Petty et al. [1,2] discussed key aspects of SPMD sample processing and a number of extracting steps of trapped pollutants from the lipid are involved. Moreover, the sampler is not very selective which can give identification problems for very dirty samples such as waste water unless when using selective detector. Fig. (7) shows chromatograms obtained after analysis of extract from SPMD. Recently, microwave-assisted extraction has been proposed as a faster method to re-extract the trapped compounds [22]. To check for quality control and assurance in SPMDs, in one study [26], the samplers were spiked with standard solutions of PAHs, PCBs and OCPs in hexane. The recovery in this case was between $92 \%$ and $110 \%$ for PAHs, between $105 \%$ and $115 \%$ for PCBs and between $74 \%$ and $82 \%$ for non-polar pesticides.

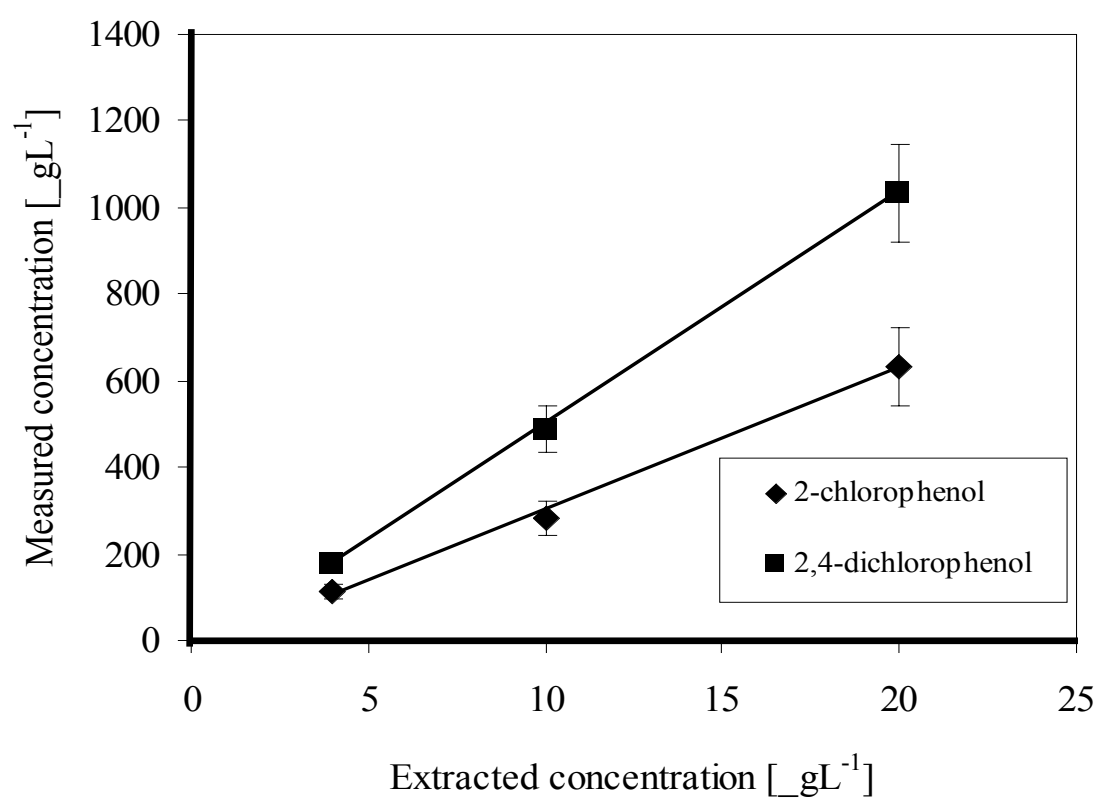

Fig. (6). Plot of the measured concentration against extracted concentration in river water after 72 hours extraction. Taken from ref. [18]. 


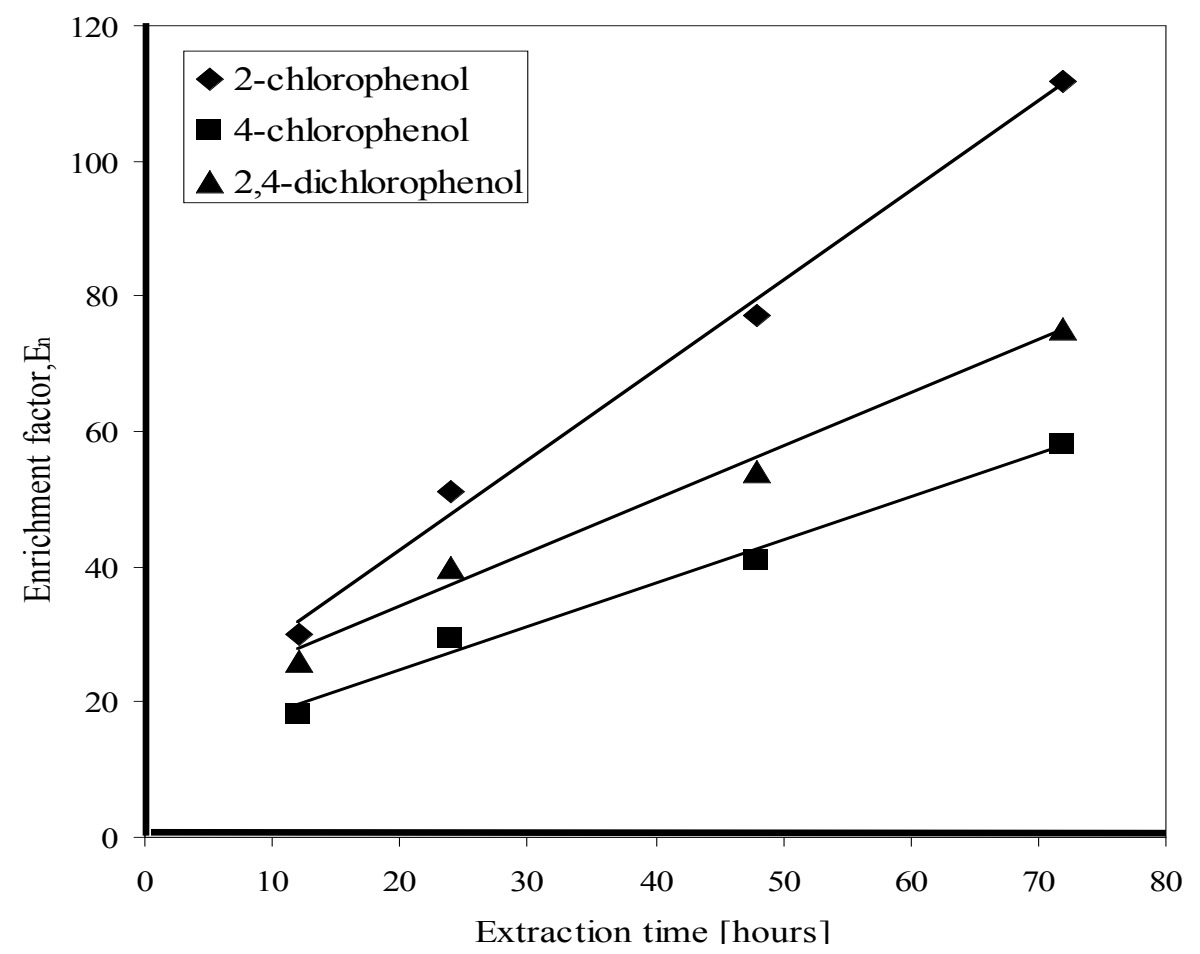

Fig. (7). Linearity of uptake by the MAPS over 72 hour period. Taken from ref. [18].

\section{Solvent Filled Dialysis Bag}

This was the first sampler to be introduced for monitoring of compounds in water by Sodergren [3]. In this case, a dialysis membrane made of regenerated cellulose in the form of a tube is filled with an organic solvent, typically hexane. The selectivity of the sampler is based on differences of the dissolution into the membrane and also on pore size. It was thought to mimic bioconcentration just like in fish and other invertebrates. The dialysis membrane has also a cut off that excludes large molecules, similar to biological membranes. The sampler is not very selective but can still be used to trap as many compounds as possible including the non target ones. The loss of the organic solvent over time during exposure is one other disadvantage of the sampler. However, loss of solvent during exposure has been said to prevent biofouling on the surface. The solvent-filled dialysis bag passive sampler has not gained much popularity thus far. However, this sampler is very simple and cheap.

\section{Other Passive Samplers}

More passive samplers for monitoring organic compounds in water bodies have been reported. These include the negligible depletion-solid phase microextraction (nd-SPME). This uses a polymer coating of an optical silica fiber just like in traditional SPME. However, in this case, the fibre is exposed in the headspace above the sample or directly in the sample without any stirring. During extraction there is equilibrium between the bound and free fraction of analyte, the depletion of the free fraction is negligible and the binding matrix does not affect the process [37]. Nd-SPME has the advantages of the SPME technique of using little organic solvents, simple and precise [38]. The specific application to measure the free fraction by SPME was introduced by Kopinke et al., and Vae et al. [37]. Nd-SPME has the disadvantage of offering only small amounts of the sample for analysis that may lead to detection limit problems. Another new sampler based on the SPME technique analysis of the samples has been reported by Pawliszyn's research group [39]. This is referred to as the polydimethysiloxane (PDMS) rod passive sampler as it uses a PDMS rod as a collector of analytes from water samples. The uptake and desorption kinetics of the sampler have been investigated in a flow through system. Linear isotropic absorption and desorption were observed. Jonsson's research group [40] has also reported to have developed an equilibrium sampling through membranes (ESTM) for measuring the free fraction of ionizable organic compounds in water. This uses the same principles of supported liquid membrane extraction technique. It is similar to the MAPS only that here a porous polypropylene hollow fiber membrane $(280 \mu \mathrm{m}$ i.d., $50 \mu \mathrm{m}$ wall thickness, $0.1 \mu \mathrm{m}$ pore size, $15 \mathrm{~cm}$ long) is used. This is then impregnated with non-polar organic solvent (undecane) in the fiber wall as a liquid membrane. Extraction conditions are set such that concentration of the free fraction in the sample is not depleted, thus maintaining the equilibrium involved. Other reported passive samplers for water pollutants are active carbon filled acrylic polymer sampler [41], carbon filled silicone sampler [42], silicone sampler with or without resin [25], ceramic dosimeter [43], trimethyl pentane passive sampler that uses a polymer tube filled with isooctane as receiving phase $[44,45]$.

\section{APPLICATIONS OF PASSIVE SAMPLERS}

About $76 \%$ of the applications have used SPMDS [10]. Much of the applications on the new passive samplers are concerned with comparison with spot sampling for quality assurance purposes $[15,16,34]$. Reviews on the applications of SPMDS to water monitoring have also been reported [11, 12]. It is the most applied sampler with compounds ranging from pesticides and biocides, organochlorines and organoha- 
logens, to aromatic and alkylated aromatic compounds [11, 12]. Verwei et al. [26] assessed the bioavailable PAH, PCB and OCP concentrations in fresh water sites in and around the city of Amsterdam using SPMDs. The study also compared the PAH concentrations in SPMDs to those found in sediments and caged carp. A significant correlation was observed between biliary PAH metabolite levels in fish and aqueous concentrations estimated with SPMDs.

The newly developed PDMS rod passive sampler [39] has been tested in field sampling for polyaromatic hydrocarbons in water in the Hamilton Harbour in Canada. In this case the results were compared with spot sampling using SPME direct extraction. This comparison indicated a strong agreement between the two methods at $1 \mathrm{~m}$ depth and lower ppt concentrations. At lower depths, the concentrations of fluoranthene and pyrene could not be detected by the SPME since only small volume was extracted. The PDMS rod on the other hand gives the TWA concentrations, thus giving lower detection limits. The POCIS sampler has been compared to standard watercolumn sampling for qualitative determination of organic contaminants associated with wastewater effluents entering New Jersey stream (USA) [34]. In another study, the POCIS was used to evaluate the level of contamination of headwaters by oestrogenic hormones from livestock farms in the U.K [35]. The total estrogenic activity in concentrates was analysed using the Yeast Estrogen Screen (YES) calibrated against 17B estradiol (E2) while oestrone (E1) and 17 ethinylestradiol (EE2) were analysed by liquid chromatography - mass spectrometry (LC-MS/MS). In this case the YES results were confirmed by the chemical analyses. More organic contaminants in this case were identified in the passive sampler extracts compared to the standard water-column sampling method. This provided evidence of the use of passive samplers for the detection of chemicals that dissipate easily or enter the watershed via an episodic event. Vrana et al. [27] compared the field performance of the MESCO to spot sampling. A good correlation of contaminant patterns and water concentrations was obtained by the two sampling techniques.

\section{CONCLUSIONS}

It is clear that interest in the use and development of passive samplers for monitoring water pollutants is on the increase. Passive samplers will soon be viewed as alternative techniques in water monitoring. Commercially available passive sampler will also increase. Research on passive samplers will later likely to lead to the developments of more samplers that have selective sorbents and/or those that are cheap and simple with no need of further clean up of the extracts.

\section{REFERENCES}

[1] Wilford, B.H.; Harner, T.; Zhu, J., Shoeib, M.; Jones, K.C. Environ. Sci. Technol., 2004, 38, 5312 .

[2] Huckins, J.N.; Tubergen, M.W.; Manuweera, G.K. Chemosphere, 1990, 20, 533.

[3] Södergren, A. Environ. Sci. Technol., 1987, 21, 855.

[4] Kingston, J.K.; Greenwood, R.; Mills, G.A.; Morrison, G.M.; Person, L.B. J. Environ. Monit., 2000, 2, 487.

[5] Gorecki, T.; Namiesnik, J. Trends Anal. Chem., 2002, 21, 276.

[6] Boglione, C.; Costa, C.; Giganti, M.; Cecchetti, M.; Di Dato, P.; Scardi, M.; Catudella, S. Ecological Indicators, 2006, 6, 712.
Goarlay, C.; Miege, C.; Noir, A.; Ravelet, C.; Garric, J.; Mouchel. J.M. Chemosphere, 2005, 61, 1734.

[8] Richardson, B.J.; Zheng, G.J.; Tse, E.S.C.; Lam, P.K.S. Chemosphere, 2001, 45, 1201.

[9] Phillips, D.T.H. Quantitative aquatic biological indicators: Their use to monitor trace metal and organochlorine pollutioin. Applied Science Pub. London, UK. 1980.

[10] Vrana, B.; Mills, G.A.; Allan, I.J.; Dominiak, E.; Svensson, K.; Knutsson, J.; Morrison G.; Greenwood, R. Trends Anal. Chem., $\mathbf{2 0 0 5}, 24,845$

[11] Lu, Y.; Wang, Z.; Huckins, J.N. J. Aquatic Tox., 2002, 60, 139.

[12] Petty, J.D.; Orazio, C.E.; Huckins, J.N.; Gale, R.W.; Lebo, J.A.; Meadows, J.C.; Echools, K.R.; Cranor, W.L. J. Chromatogr. A, 2000, $879,83$.

[13] Kot, A.; Zabiegala B.; Namiesnik, J. Trends Anal. Chem., 2000, 19, 446.

[14] Stuer-Lauridsen, F. Environ. Pol., 2005, 136, 503

[15] Vrana, B.; Mills, G.A.; Dominiak, E.; Greenwood, R. Environ. Pol., 2006a, 142, 333.

[16] Vrana, B.; Mills, G.A.; Kotterman, M.; Leonards, P.; Booij, K.; Greenwood, R. Environ. Pol., 2007b, 145, 895.

[17] Vrana, B.; Popp, P.; Paschke, A.; Schuurmann, G. Anal. Chem., 2001, 73, 5191.

[18] Chimuka, L.; Nemutandani, T.; Cukrowska, E.; Tutu, H. JEM, 2008, 10, 129 .

[19] Sabaliunas P.; Sodergren. A. Environ. Pol., 1997, 96, 195.

[20] Mergesa, N.; Chimuka, L.; Solomon, T.; Jonsson, J.A. J. Sep. Sci., 2001, 24, 567.

[21] Richardson, B.J.; Lam, P.K.S.; Zheng, G.J.; Mc Clellan, K.E.; De Luce-Abott, S.B. Marine Pol. Bulletin, 2002, 44, 1372.

[22] Yusa, V.; Pastor, A.; de la Guardia, M. Anal. Chim. Acta, 2005 $540,355$.

[23] Chimuka, L.; Cukrowska, E. LC-GC North America, 2006, 24, 118.

[24] Booij, K.; Van Drooge, B.L. Chemosphere, 2001, 44, 91.

[25] Booij, K.; Smedes, F.; Van Weerlee, E.M. Chemosphere, 2002, 46, 1157.

[26] Verweij, F.; Booij, K.; Satumalay, K.; Van der Molen, N. Chemosphere, 2004 54, 1675.

[27] Vrana, B.; Paschke A.; Popp, P. Environ. Pol., 2006c, 144, 296.

[28] Petty, J.D.; Huckins, J.N.; Alvarez, D.A.; Brumbaugh, W.G.; Cranor, W.L.; Gale, R.W.; Rastall, A.C.; Jones-Lepp, T.L.; Leiker, T.J.; Rostad C.E.; Furlong, E.T. Chemosphere, 2004, 54, 695.

[29] Baltussen, E.; Sandra, P.; David, F.; Cramels, C. J. Micro Column Separations, 1999, 11, 737.

[30] Paschke, A.; Schwab, K.; Brummer, J.; Schuurmann, G.; Paschke, H.; Popp, P. J. Chromatogr. A, 2006, 1124, 187.

[31] Chimuka, L.; Megersa, N.; Norberg, J.; Mathiasson, L.; Jonsson, J.A. Anal. Chem., 1998, 70, 3906

[32] Jonsson, J.A.; Mathiasson, L. Trends Anal. Chem., 1999, 18, 325.

[33] Alvarez, D.A.; Petty, J.D.; Huckins, J.N.; Jones-Lepp, T.L.; Goddard, J.P.; Manahan, S.E. Environ. Tox. Chem., 2004, 23, 1640.

[34] Alvarez, D.A.; Stackelberg, P.E.; Petty, J.D.; Huckins, J.N.; Furlong, E.T.; Zaugg, S.D.; Meyer, M.T. Chemosphere, 2005, 61, 610.

[35] Matthiessen, P.; Arnold, D.; Johnson, A.C.; Pepper, T.J.; Pottinger, T.G.; Pulman, K.G.T. Science Total Environ., 2006, 367, 616.

[36] Huckins, J.N.; Petty, J.; Lebo, J.A.; Orazio, C.E.; Prest, H.F.; Tillit, D.E.; Ellis, G.S.; Johnsson, B.T.; Manuweera, G.K. Techniques in Aquatic Toxicology. Lewis CRC press, Boca Rotu, FL, USA, 1996.

[37] Heringa, M.; Hermens, J.L.M. Trends Anal. Chem., 2003, 22, 575.

[38] Arthur, C.L.; Pawliszyn, J. Anal. Chem., 1990, 62, 2145.

[39] Zhao, W.; Ouyang, G.; Alaee, M.; Pawliszyn, J. J. Chromatogr. A, 2006, $112,112$.

[40] Liu, J.F.; Jonsson, J.A.; Mayer, P. Anal. Chem., 2005, 77, 4800.

[41] Digiano, F.A.; Elliot, D.; Leith, D. Environ. Sci. Technol., 1989, 22,1365 .

[42] Zhang, G.Z.; Handy, J.K. J. Environ. Sci. Health A, 1989, 24, 279.

[43] Martin, H.; Pa Herson, B.M.; Davis, G.B. Environ. Sci. Technol., 2003, 37, 1360 .

[44] Zabik, J.M.; Aston, L.S.; Seiber, J.N. Environ. Toxicol. Chem., 1992, 11, 765 .

[45] Peterson, S.M.; Apte, S.C.; Batley, G.E.; Coade, C. Chem. Spec. Bioavail., 1995, 7, 83 . 